\title{
New Technology of Cotton Sowing
}

\author{
Kamaridin Urinovich Komilov', Aypara Djoldasova Kurbanova ${ }^{\mathbf{2}}$, Gafurjan Israilovich Muhamedov ${ }^{\mathbf{3}}$ \\ ${ }^{1}$ Candidate of Technical Sciences, Associate Professor, \\ Chirchik State Pedagogical Institute, \\ Chirchik, Republic of Uzbekistan, \\ dos650922@gmail.com \\ ${ }^{2}$ Candidate of Chemical Sciences, Head of the Department, \\ Chirchik State Pedagogical Institute, \\ Chirchik, Republic of Uzbekistan \\ ${ }^{3}$ Doctor of Chemical Sciences, Professor, Rector \\ Chirchik State Pedagogical Institute, \\ Chirchik, Republic of Uzbekistan
}

\section{ABSTRACT}

The possibility of using bulk waste of the chemical industry - phosphogypsum as a useful resource is considered. The results of scientific research and practical experience convincingly proved the technical feasibility and feasibility of using phosphogypsum in the national economy instead of traditional types of natural raw materials. A brief description of phosphogypsum, promising areas for its processing, and some statistics are presented.

The article is about the use of chemical ameliorant based on phosphogypsum for effective feedingin various soil and climatic zones for cereals, vegetables, industrial and other crops, to increase the yield of cotton and the technological quality of its fiber. That the use of phosphogypsum as a chemical ameliorant improves the chemical, physical and water-physical properties of saline soils.

The article describes a new technology of cotton sowing in the conditions of the Republic of Uzbekistan. The technology of soil treatment and methods of measuring for preventing crust formation are analyzed. The used mechanisms, units and are justified.

Key Words

phosphogypsum, chemical ameliorant, chemical reclamation, salinization, gypsum, calcium dihydrate, interpolymer complex, composite material, technology, cotton sowing, soil treatment.

\section{Introduction}

The rapid pace of development of industry, energy, metallurgy, metalworking, chemical, petrochemical and other industries, as well as areas of engineering, construction and household activities entail the inevitable generation and accumulation of industrial waste on a global scale. And one of the main types of waste is waste from the chemical industry.

So, in the production of mineral fertilizers, various types of waste are generated, among which phosphogypsum is a waste of the production of phosphate fertilizers [2]. It should be noted that at present, a significant layer of problems of a geoecological nature is generally observed, associated primarily with extensive forms of environmental management, environmental degradation for various reasons [3; $4]$, including the irrational management of many sectors of nature management [5].

The main leaders in the production of phosphate raw materials and products made from it are the United States (43.97 million tons), China (29.0 million tons), Morocco (23.59 million tons) - data for 2000 and Russia ( 10.29 million tons) data for 2006. It should be noted that our country traditionally occupies one of the leading places in the world market of phosphate raw materials [1]. 
In Russia, the largest holdings in the mineral fertilizer industry are Fosagro, EuroChem and Acron [7].

Methods. Extraction phosphoric (orthophosphoric) acid (EPA) is the basic product in the production of most of the elemental phosphorus, concentrated simple and complex fertilizers, and feed phosphates. In our country, Khibiny Apatite concentrate is used for its production. In industry, there are two methods for producing phosphoric acid: thermal and extraction. The thermal method of producing phosphoric acid consists in the high-temperature reduction of phosphates and sublimation of elemental phosphorus in electric furnaces, which is then oxidized to phosphoric anhydride, which forms phosphoric (thermal) acid during hydration. The main method for producing EPA is the displacement of phosphoric acid from raw materials by strong acids. As the displacing acid can be used: sulfuric, nitric, phosphoric, as well as mixtures thereof. Over $70 \%$ of natural phosphate raw materials worldwide are processed using sulfuric acid, hence the name of the production method - sulfuric acid (extraction). Thermal acid is cleaner than extractive, even when using low quality raw materials, which is its advantage. However, at present, there is a decrease in the production of thermal acid, since the process of its production seems to be very energy intensive. In this regard, it is more expensive. However, at present, there is a decrease in the production of thermal acid, since the process of its production seems to be very energy intensive. In this regard, it is more expensive. However, at present, there is a decrease in the production of thermal acid, since the process of its production seems to be very energy intensive. In this regard, it is more expensive.

The decomposition of apatite concentrate with sulfuric acid is described by the following equation (phosphoric acid dissolution of fluorapatite):

$$
\begin{gathered}
\mathrm{Ca}_{5}\left(\mathrm{PO}_{4}\right)_{3} \mathrm{~F}+5 \mathrm{H}_{2} \mathrm{SO}_{4}+n \mathrm{H}_{3} \mathrm{PO}_{4}+\mathrm{mH}_{2} \mathrm{O} \rightarrow(n \\
+ \text { 3) } \mathrm{H}_{3} \mathrm{PO}_{4}+5 \mathrm{CaSO}_{4} \cdot \mathrm{mH}_{2} \mathrm{O}+\mathrm{HF}
\end{gathered}
$$

Phosphoric acid is extracted during the reaction, and calcium sulfate and fluorinated gases are also formed.
Depending on the temperature and concentration conditions of the process, calcium sulfate crystalline hydrates (solid phase) may precipitate in the form of dihydrate, hemihydrate or anhydrite. These forms of the existence of calcium sulfate when changing the mode of conducting the process can go from one to another. Accordingly, dihydrate, hemihydrate and anhydrite methods for the production of phosphoric acid are isolated.

Calcium sulfate dihydrate or hemihydrate formed as a by-product due to the content of P2O5 impurities in them (undecomposed phosphate, undisturbed phosphoric acid, co-crystallized P2O5) is called phosphogypsum or phosphohemihydrate, respectively. But when considering the problems of transportation, storage and use, both products are usually called phosphogypsum [6; 8; nine].

Phosphogypsum is a white to gray color finely dispersed, close to monomineral powder, having high humidity when leaving the chemical plant, according to various sources, from 25 to $45 \%$. Its chemical composition may depend on the type of phosphate feedstock, production method and method of storage [8; fifteen].

Removing a by-product involves choosing the most reliable and economical way to transport and store it, taking into account the specific conditions of each enterprise. Currently, two main directions of phosphogypsum utilization are practiced in the world: discharge into water bodies (rivers, seas) and laying on land. The first method is practiced only by some states: Morocco, Tunisia, the countries of South Africa and Mexico, which is approximately 5\% [10]. Groundbased storage of waste requires special engineering structures for storage and is carried out in the so-called "dry" dumps or in hydraulic dumps (reclaimed or bulk gypsum storage tanks) $[11,12]$. The drive has one or another name depending on the method of transportation:

- "Dry" (semi-dry selection) - with the movement of wet waste without neutralization by road. In Russia, this method is practiced, for example, by Phosphorit Production Association (Kingisepp, Leningrad Region) and Apatit BF JSC (Balakovo, Saratov Region).

- "Wet" (hydrotransport) - the waste is fed to the dump by hydrotransport via a slurry 
pipeline after neutralizing acids in the liquid phase with lime and repulping. Examples are enterprises: OJSC Metakhim (Volkhov, Leningrad Region), Production Association Ammofos (Cherepovets) and EuroChem-BMU LLC (Belorechensk, Krasnodar Territory).

In the formation of this kind of mining structures are guided, first of all, by economic and environmental principles, the meaning of which is to ensure maximum technical and economic efficiency with minimal disturbance of the natural environment. One way or another, the ecological balance is disturbed, which is associated with a change in the natural landscape, pollution of the soil cover, deterioration of the atmospheric air, changes in the condition and properties of rocks that form the foundations of dumps, hydrological and hydrogeological regimes, etc. [13,14].

The problem of using phosphogypsum as a secondary raw material for the production of liquid products has been relevant since the 60s. XX century. The results of numerous studies and practices convincingly proved the technical feasibility and feasibility of using phosphogypsum in the national economy instead of traditional types of natural raw materials [15]. This is due to the content in gypsum from 80 to $98 \%$ gypsum, which allows it to be attributed to gypsum raw materials. Here it should be noted the most promising areas of using phosphogypsum as a valuable large-tonnage secondary resource:

- in agriculture for chemical reclamation of acid and solonetzic soils and composting with organic fertilizers;

- in the cement industry, as a mineralizer - additives to the raw material mixture and as a regulator of setting speed - instead of natural gypsum;

- for the production of gypsum binders and products, filler in the manufacture of plastics, glass;

- $\quad$ in the construction of roads, the construction of buildings and structures;

- $\quad$ at arrangement of sea and coastal zones;

- for the production of sulfuric acid, etc.

Production of row cotton- is the main port of agricultural culture irrigatablt agriculture. All countries of mid asian region
Diggerence in weather and soil conditions low maintenance of humus, diggerent level of underground water create additional digiculties and reguire extraordinary way to decide appearing problem. Changing of weather conditions, especially, in north zone troubles increase of effective temperature necessary for gull ripening fruits and succesgue completion of technological cycle. It is typical for some regions concerning high figures of mid month norm of precipitation before and in sowing season. Additional essential conditions creating negative cjnseguence is abrupt inerease of temperature of air often accompanying with wind which promote quick dring up drying of soil and sowing seeds.

\section{The cotton sowing}

For getting healthy unanimous young growth it is necessary to ensure achievement of optimal temperature interval, preservation of humidity of soil and prevent after rain crustformation. Bringing of oggective herbicide plays important role. That is why it is necessary for getting high crops to create new technjljgy of sowing of cotton excluding up growing, clecidinging next questions

- Covering of soil by mydbrew that prevent formation soil crust after rain.

- Congormity to power of gap of crust by growing

- Achievement optimal cumulation of sun energy to energies appearance of young growth

- Covering effective herbicide

- Elaboration of technology of out ofgrawing by simultaneous covering of multing of material, herbicide

- Ensuring of combination usable nultimaterials chemical means of protection and their ecological safety.

Best of all it is necessary to inculcate new step by step technology of outub growing, cultivations harvesting for systematic reducing cotton- row costs Especially a great expenditures sowing material spends in up growing achieving in the middle to $60 \%$ grow common sown area.

Destruction soil crust that was formed on the surface of soil after strong rain in the period after sowing is especially difficult 
effectively of given method

1-2 days, in another case, sprouts that have not begun to shoot through soil crust are depressed or lost to get over soil crust either plawring or cultivation are conducted with powerful improved work bodies. There is delay of growth in any way unevenness of young growth in all area, breach of technology of cultivation in all way of vegitation. What is leading to different lowering of crop, increasing intact production costs.

Known ways of guaranteed getting of early healthy young growth with using polietileym covering is used in regions of republic with dense population because of difficulties of mechanization all ways of given technology.

That is why at given moment struggle with (korking) after rain conducted in dependence on condition of seeds, harrows zigzag is used in one line across the field in first stage of for nation of (grow), but if the seeds have not appeared on surface of soil hinge rotary hoes $(\mathrm{MVN}-5,4)$ in the line of sowing or tractor cultivators provided improving work organs are used.

In that way, for struggle with soil crust, especially for destruction of formed crust very good power and means are spent.

Measures, directed for preventing of crust formation is only accept for lowering of work expenditure of 100 kilograms of raw cotton.

Our investigations of many years showed that preventing of sowing formation is more acceptable. Given method of soil treatment regulates and weakens evaporation of moisture, promotes cumulating of sun energy and therefore decrease amplitude of fluctuation in temperature of soil in the period of the day, optimizes feeding rate of- growth of sowing material. In given case for cumulating of heat is responsible addition of dark coloration or origin.

Herbicide of industrial production is against weeds of cotton. For preparation solution of polycomplex aggregate is used with volume 10001 . That diagram is shown in schedule in figure 1

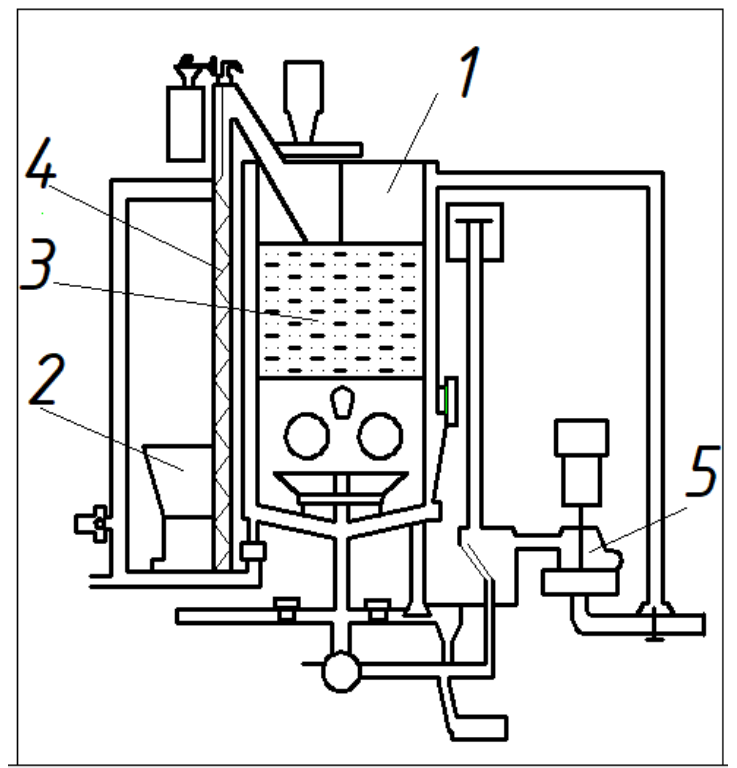

1. Reactor

2. Receiving bunker

3. Mixer

4. Vertical conveyer

5. Pump

Figure 1. Diagram system of aggregate.

To prepare solution for reactor (1) flood about 7001 . Of water, component 1 is loaded in bunker (2), mixing by help of mixer (3), through a vertical conveyer (4) component 1 is given.

After full solution which is going without stopping mixer flood liquid components (component 3 is dissolved for coneertration $5 \%$ ) and calculated quantity of component 4 and cotoran. Then common volume of liquid increase to soil and ready solution is going to work tractor capacity of 
mechanism of plotting or another capacity of sportation of solution through pump emulgator 5. For preparation so liters of solution $25-30 \mathrm{~min}$ is spent.

For covering surface of soil by polycomplex solution with cotton sowing at the same time system usable at present time for potting herbicides with some changing is used:

1. Place 2 additional tank from system (PHG-4) in fore-part of tractor frame when common volume is about soil.

2. Substitute hose of high pressure (GOST-6286-73) for conduit of system (PHG-

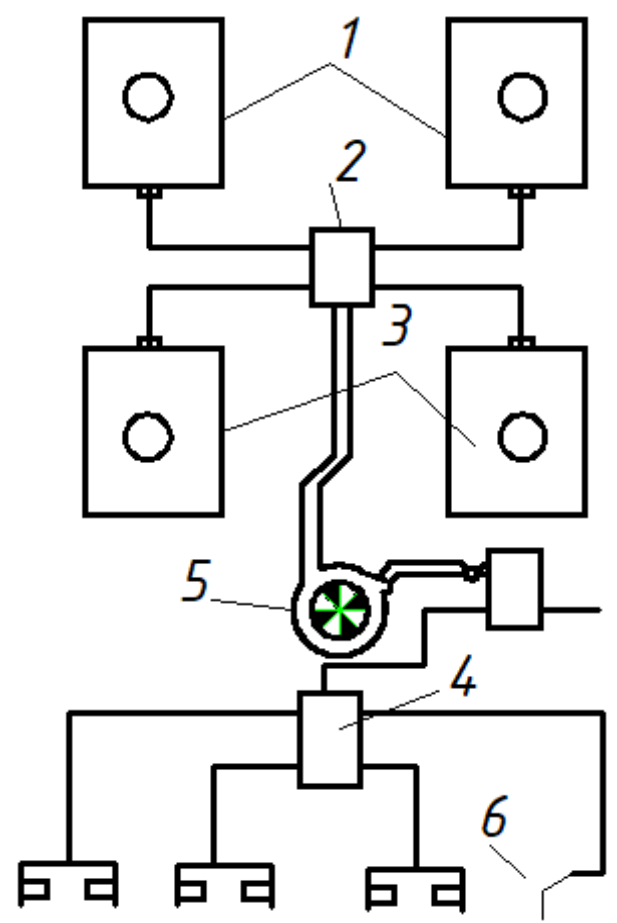

Figure 2. Diagram of plotting aggregate of solution (PC)
4) for preventing gap and increasing capacity of system.

3. Place unification of supply of liquid on the frame from your tanks into pump.

Thus. Conducted additional changes don't break traditional technology of cotton sowing, only decrease productivity of aggregate work by decreasing speed of tractor and loosing time, but refueling by solution.

Work solution of polycimplex with herbicides and warn colour is brung like a ribbon $15 \mathrm{~cm}$ wide and common expense is 800-1000 1/(ga).

1. capacity

2. unit of supply of liquid

3 . reduction gear

4. pump

5. distributor

6. pulverize
It is necessary to mention that in dependence on exact volume of usable solution require correction of concentration of cotoran, within optimal rate on hectare. Quantity of additional component 4 clarify in the rate of $4,5-5 \mathrm{~kg} / \mathrm{ga}$.

\section{Discussion}

During using of given technology improve agrophysical conditions of growth of entering seeds. It is expressed in next: created cover promotes plarungel of moisture of soil, daily comulation of sun energy, prevents washing off herbicides from zone of sowing seeds, decreasing crust formation after rain in
2-3 times.

Proceeding from agrochemical description of soil conditions, prognosis of intensity and quaint by of precipitation before appearance of young growth, middle temperature of air and taking into account extremal weather conditions using suggested method it is going to be possible to except annual up-growing, leading to great waste of work resources, high-quality seeds and getting of high crop with the least expenditures.

Our researches of many years showed that it is possible to reach exception of upgrowing with using of given technology, and getting health early growth with passing ahead 
of growth and leading to increasing quantity and quality of crop in 15-20\%.

The problem was solved in such a way that several trays with certain pore sizes were placed next to each other along the furrow, at a distance of the length of run-off of irrigation water. Water saving is achieved by eliminating the discharge of water, as well as ensuring uniform soil moisture along the entire length of the furrow.

The irrigation tray is used as follows: water from the dispensers (Fig. 2.) (1), through a filter (2) made of polymer material, enters the trays and through it enters the soil. Water consumption is governed by the size of micropores (3) obtained by the selection of percentages of components of the polymer material. The filter (2), which is made of the same material, eliminates clogging of the trays. Irrigation water is supplied to the soil through the pores of the tray in the form of droplets. Pore sizes can be adjusted by changing the composition of the CM. The width of the trays is $10 \mathrm{~cm}$, the depth is $12 \mathrm{~cm}$, and the length is $100 \mathrm{~cm}$. By connecting them in series, the required length can be achieved.

The distribution of irrigation norms by soil layers was determined according to the variants of small-plot experiments in triplicate. Watering was carried out without discharge. The soils of the site are automorphic, medium loam in terms of mechanical composition. The optimal rate of absorption of water into the soil was $0.016-0.017$ $\mathrm{m} / \mathrm{h}$. The level of moistened soil layers at the beginning and end of the furrow was 50 and 45 $\mathrm{cm}$ for the first, $62-51 \mathrm{~cm}-$ second and $81-69 \mathrm{~cm}$ third watering, respectively.
The balance equation of irrigation norms has been compiled:

$$
m b r=m 1+m 2+m 3
$$

where mbr - irrigation rate supplied to the site, $\mathrm{m} 3$ / ha;

$\mathrm{m} 1$ - estimated irrigation rate, $\mathrm{m} 3$ / ha;

$\mathrm{m} 2$ - water loss due to evaporation, $\mathrm{m} 3$ / ha;

m3 - soil moisture below the calculated layer, $\mathrm{m} 3$ / ha

Irrigation rates by layers were determined by the size of soil moisture before and after irrigation after $3,5,7,10,15$ days and were calculated by the formula:

$$
\mathrm{m}=100 \mathrm{Hd}(\mathrm{Pnv}-\mathrm{Pf}),
$$

where $\mathrm{N}$ is the calculated soil layer, $\mathrm{m}$;

$\mathrm{d}$ - soil density, $\mathrm{t} / \mathrm{m} 3$;

Rnv, Rf - humidity at the lowest moisture capacity and actual before irrigation, $\%$ of the mass of dry soil.

When irrigating with water flow rates of 0.4-0.6 1 / s with irrigation rates of gross 600-650 $\mathrm{m} 3$ / ha, when the norm below the calculated layer was $20-35 \mathrm{~m} 3 /$ ha $(3.3-5 \%)$ and water loss for evaporation - 30-33 $\mathrm{m} 3 /$ ha $(5 \%)$, the calculated irrigation rate will be $550-581 \mathrm{~m} 3 / \mathrm{ha}$. The use of relatively lower irrigation rates of up to $600 \mathrm{~m} 3$ / ha and compliance with irrigation regimes ensured an increase in yield by $3.4 \mathrm{c} / \mathrm{ha}$, in contrast to the control plot [19]. 


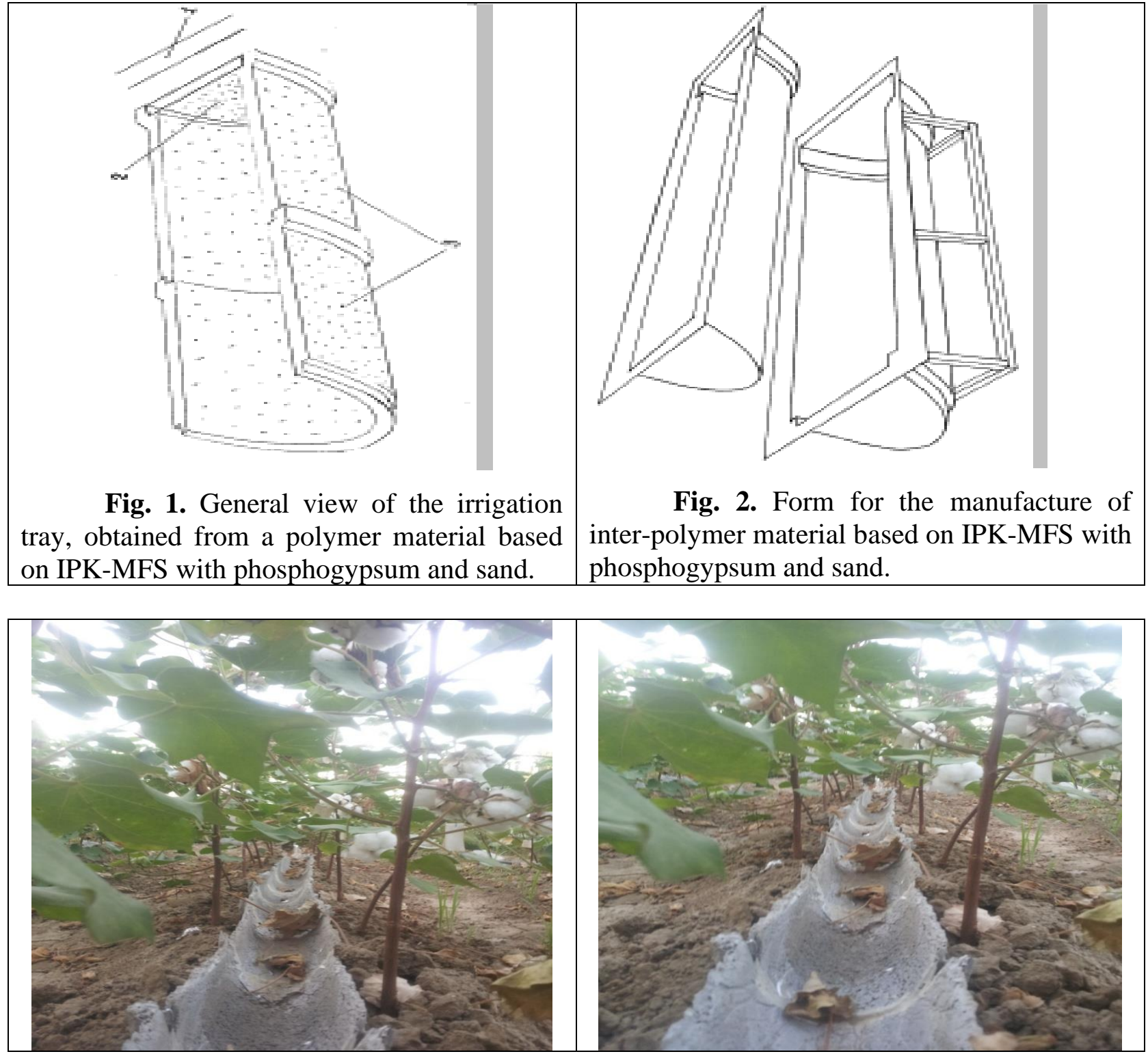

Fig. 3. Practical application of the obtained porous material from phosphogypsum to reduce the irrigation rate.

Conclusion. According to forecasts, by 2040 the amount of waste can double. The question of bringing phosphogypsum to such a state that it is possible to use it whole and it is cost-effective, or to assimilate waste in the natural environment without compromising its natural state, is as relevant as ever. Thus, the current problems of nature management and waste generation are interrelated, which requires a phased and at the same time comprehensive solution.

It was found that the developed interpolymer materials with excess sodium carboxymethyl cellulose salt can be used as highly swelling hydrogels and an anti-filter screen, and with excess urea-formaldehyde resin and dispersed fillers to save irrigation water (uniform distribution of water along the length of the irrigation furrow). The fact of their role in saving water and cotton productivity is confirmed.

\section{References:}

1. Angelov A.I., Levin B.V. Chernenko Yu.D. Phosphate raw materials // Reference. - M.: Nedra-Business Center LLC. 2000.120 s.

2. Halperin A.M., Förster V., Chef H.-J. Manmade arrays and the protection of natural resources: Textbook for universities: 2 
volumes. - M.: Publishing house of Moscow State University, 2006. T. 1: Bulk and alluvial massifs. $391 \mathrm{p}$.

3. Larionov M.V., Smirnova E.B., Burdin M.V. Environmental degradation in the zone of influence of technogenic and agricultural objects // Bulletin of the Samara Scientific Center of the Russian Academy of Sciences. 2011. V. 13. No. 1-6. S. 1347-1349.

4. Larionov N.V., Larionov M.V. Heavy metals as a factor of technogenic impact on soils of urboecosystems of the Saratov region // Bulletin of KrasGAU. 2009. No. 11. P. 2226.

5. Larionov N.V., Larionov M.V. Ecological features of nature management in the Middle and Lower Volga // Natural and mathematical sciences in the modern world. 2015. No. 28. S. 58-64.

6. Meshcheryakov Yu.G., Fedorov S.V. Industrial processing of phosphogypsum. St. Petersburg: Stroyizdat St. Petersburg, 2007 .-- 104 p.

7. Phosphate and raw material base of Russia: new technologies and development prospects / Nepryakhin A.E., Senators P.P., Karpova M.I. // Mining equipment. 2009. No. 4. P. 136-144.

8. Phosphogypsum and its use / V.V. Ivanitsky, P.V. Klassen, A.A. Novikov et al. - M .: Chemistry, 1990 .-- 224 p.

9. Best Available Techniques for Pollution Prevention and Control in the European Fertilizer Industry, Booklet No. 4 of 8: Production of phosphoric acid, European Fertilizer Manufacturers' Association, EFMA B-1160, Brussels, Belgium.

10. Fuleihan, Nadim F., Phosphogypsum disposal - The pros \& cons of wet versus dry stacking // Florida, 2011 .-- 11 p.

11. Gennari RF, Garcia I., Medina NH, Silveira MAG Phosphogypsum analysis: total content and extractable element concentrations, International Nuclear Atlantic Conference. 2011, Brazil.

12. Hilton, Julian, Phosphogypsum (PG): Uses and Current Handling Practices Worldwide, Proceedings of the 25th Annual Lakeland Regional Phosphate Conference. October 1314, 2010, London UK.
13. Larionov MV Scheme technogenic stress of natural and artificial landscapes of the Saratov and Volgograd regions // Theoretical and applied questions of science and education: at 4 pm Part 15. Tambov, 2015. P. 8-9.

14. Pe'rez-Lo'pez R., A' lvarez-Valero AM, Nieto JM Changes in mobility of toxic elements during the production of phosphoric acid in the fertilizer industry of Huelva (SW Spain) and environmental impact of phosphogypsum wastes / J. of Hazardous Materials 148 (2007) 745-750.

15. Tayibi H., Choura M., López FA, Alguacil JA, López-Delgado A. (2009). Environmental impact and management of phosphogypsum (Review). J. Environ. Manage. 90, 2377-2386.

16. Korobanova T.N. Russian and foreign experience in the utilization of phosphogypsum // Science yesterday, today, tomorrow: Sat. Art. by mater. XL Int. scientific-practical conf. No. 11 (33). Novosibirsk: SibAK, 2016 .-- S. 63-71.

17. Laktaev N.T. Theoretical substantiation of the technique of irrigation of crops on furrows: Proceedings of the Agricultural Academy. "The technique of irrigation of crops" - M., 1972. - S. 61.

18. Kambarov B.F. Improving the technique of furrow irrigation, taking into account the protection of soils from irrigation erosion in conditions of large slopes and complex reliefs: Abstract. diss. ... cand. tech. sciences. - Tashkent: 1972. - P.15.

19. Kamilov K.U. Non-stoichiometric interpolymer complexes based on urea formaldehyde resin and dispersed fillers: Diss. ... cand. tech. sciences. - Tashkent: 2005

20. Recommendations for the reclamation of solonetzic lands.- M .: Kolos, 2003 .-- 46 p.

21. Ivanitsky V.V., KlassenP.V., Novikov A.A. Phosphogypsum and its use. - M .: Chemistry, 2000 .-- 224 p. 